\begin{tabular}{|c|l|}
\hline Title & $\begin{array}{l}\text { Fertility restoration by Ifr1 in rice with BT-type cytoplasmic male sterility is associated with a reduced level, but not } \\
\text { processing, of atp6-orf79 co-transcribed RNA }\end{array}$ \\
\hline Author(s) & Ohta, Haruka; Ogino, A tsushi; Kasai, Megumi; Sano, Y oshio; Kanazawa, A kira \\
\hline Citation & $\begin{array}{l}\text { Plant Cell Reports, 29(4), 359-369 } \\
\text { https://doi.org/40.1007/300299-010-0827-7 }\end{array}$ \\
\hline Issue Date & 2010-04 \\
\hline Doc URL & http://hdl.handle.net/2115/49398 \\
\hline Rights & The original publication is available at www.springerlink.com \\
\hline Type & article (author version) \\
\hline File Information & PCR29-4_359-369.pdf \\
\hline
\end{tabular}

Instructions for use 
Published in Plant Cell Reports (2010) 29, 359-369

\section{Fertility restoration by Ifr1 in rice with BT-type cytoplasmic male sterility is associated with a reduced level, but not processing, of atp6-orf79 cotranscribed RNA}

Haruka Ohta ${ }^{1}$, Atsushi Ogino ${ }^{1}$, Megumi Kasai ${ }^{2}$, Yoshio Sano ${ }^{1}$ and Akira Kanazawa ${ }^{2}$

${ }^{1}$ Laboratory of Plant Breeding, Research Faculty of Agriculture, Hokkaido University, Sapporo 060-8589, Japan

${ }^{2}$ Laboratory of Cell Biology and Manipulation, Research Faculty of Agriculture, Hokkaido University, Sapporo 060-8589, Japan

Corresponding author:

Akira Kanazawa

Laboratory of Cell Biology and Manipulation, Research Faculty of Agriculture, Hokkaido University, Sapporo 060-8589, Japan

E-mail: kanazawa@res.agr.hokudai.ac.jp

Tel: +81-11-706-3873

Fax: +81-11-706-4933 
Abstract BT-type cytoplasmic male sterility (CMS) in rice is associated with accumulation of unprocessed dicistronic RNA containing a duplicated atp6 (B-atp6) and an unusual open reading frame, orf79, encoding a cytotoxic peptide in mitochondria. The male-sterile state of BT-type CMS is stably maintained by backcrossing the plants with line Taichung 65 (T65) that has no restorer gene and is completely suppressed by the presence of the $R f 1$ gene through the processing of B-atp6-orf79 RNA. A variant of the T65 line, T65(T), has a weak restoration function conferred by the Ifr1 gene, which is genetically independent of the $R f 1$ gene. However, little is known about the mechanism(s). In a study to examine whether the mechanism involved in fertility restoration by Ifr 1 is analogous to restoration mediated by $R f 1$, the transcript profile of B-atp6-orf79 in male-sterile plants was compared to that in fertility restored plants obtained by crossing male-sterile plants with T65(T). The cellular level of unprocessed B-atp6-orf79 RNA was reduced in the restored plants, but no change in processing efficiency or the quantity of B-atp6-orf79 DNA was detected. These results suggest that Ifr1 restores fertility through reducing either the transcription rate of B-atp6-orf79 or the stability of its primary transcripts, a mechanism distinct from that involved in fertility restoration of BT-type CMS by $R f 1$.

Keywords: cytoplasmic male sterility; fertility restorer; mitochondrial DNA; Oryza sativa; RNA processing 


\section{Introduction}

Cytoplasmic male sterility (CMS), caused by a mitochondrial-nuclear interaction that leads to a maternally inherited failure of affected plants to produce functional pollen (reviewed by Pring and Lonsdale 1985; Newton 1988; Levings and Brown 1989; Hanson 1991), is observed in more than 150 flowering plant species (Laser and Lersten, 1972). In many plant species, male fertility is restored by nuclear-encoded fertility restorer genes referred to as $R f$ (Restorer of fertility) or Fr (Fertility restorer) (Hanson and Bentolila 2004). The CMS/Rf system is commercially important for hybrid seed production because it eliminates the need for hand emasculation. Apart from its agronomic importance, CMS provides a clue to the interaction between the mitochondrial genome and the nuclear genome.

CMS is often associated with the presence of unusual open reading frames (ORFs) in the mitochondrial genome. Although these unusual ORFs that cause CMS have diverse structures, some of the mechanisms that restore fertility are common to different $\mathrm{CMS} / R f$ systems. With the exception of maize $R f 2$, all restorers so far identified affect either the transcript profile and/or the accumulation of protein produced by the CMS-associated genes in mitochondria (Hanson and Bentolila 2004). In most cases, the protein product of the CMS-determining locus fails to accumulate in the presence of a restorer allele, which is associated with either a decrease in the level of CMS-associated transcripts or in the internal processing events that truncate these transcripts (reviewed by Chase 2007). Restoration of fertility through a reduction in the level of CMS-associated protein without a change in its transcript level (Brown et al. 2003; Desloire et al. 2003; Koizuka et al. 2003) or in the copy number of the mitochondrial subgenomic DNA molecule that encodes the CMS-associated protein (Janska et al. 1998) has also been reported. In addition, Msh1, a gene encoded by the nuclear genome, suppresses mitochondrial DNA (mtDNA) rearrangement (Shedge et al. 
2007), the silencing of which induces male sterility associated with mtDNA rearrangement (Sandhu et al. 2007).

Genes that account for fertility restoration have been cloned in maize (Cui et al. 1996), petunia (Bentolila et al. 2002), rice (Kazama and Toriyama 2003; Akagi et al. 2004; Komori et al. 2004), radish (Brown et al. 2003; Desloire et al. 2003; Koizuka et al. 2003), and sorghum (Klein et al. 2005). The maize $R f 2$ gene encodes an aldehyde dehydrogenase (Cui et al. 1996), while the rest of these restorer genes encode members of the pentatricopeptide repeat (PPR)-containing protein family (reviewed by Hanson and Bentolila 2004; Chase 2007). PPR proteins are proposed to function as site-specific, RNA-binding adaptor proteins that mediate interactions between RNA substrates and the enzymes that act on the RNA (Small and Peeters 2000; Lurin et al. 2004; Chase 2007; Schmitz-Linneweber and Small 2008). It has also been known that some PPR proteins have catalytic functions in chloroplast (Nakamura and Sugita 2008; Okuda et al. 2009).

The BT-type (also called cms-bo-type) CMS is the most fully characterized system of CMS in rice. In BT-type CMS, the cytoplasm ([cms-bo] cytoplasm) derived from rice line Chinsurah Boro II causes male sterility when combined with the nucleus from rice line Taichung 65 (abbreviated as T65), that carries no restorer gene (Shinjyo, 1969). In the mitochondrial genome of Chinsurah Boro II, there is an unusual chimeric sequence called orf79, which comprises a small portion of the cox1 gene, and a sequence of unknown origin (Iwabuchi et al. 1993; Akagi et al. 1994), which encodes a cytotoxic peptide (Wang et al. 2006). The orf79 is located downstream of a duplicated copy of the atp6 gene called B-atp6, which is present in the mitochondrial genome of [cms-bo] cytoplasm in addition to the other copy of the atp6 gene called N-atp6. The B-atp6 gene is cotranscribed with orf79 and produces a 2.0-kb RNA (B-atp6-orf79 RNA), and accumulation of this RNA molecule is associated with CMS (Iwabuchi et al. 1993; Akagi et al. 1994). 
Fertility restoration of BT-type CMS is controlled by a nuclear locus, $R f 1$ (Shinjyo 1984). The Rf1 gene also restores fertility against LD-type CMS, which involves a cytoplasm containing a B-atp6-orf79 variant (Itabashi et al. 2009). The Rf1 gene has been cloned and shown to encode a PPR-containing protein that promotes the processing of B-atp6-orf79 RNA in mitochondria (Kazama and Toriyama 2003; Akagi et al. 2004; Komori et al. 2004). A recent study indicated that the Rf1 locus is a complex locus comprising two $R f$ genes, $R f 1 a$ and $R f 1 b$ (Wang et al. 2006). In the presence of the $R f 1 a$ gene, the cotranscribed 2.0-kb B-atp6-orf79 RNA is processed into 1.5-kb RNA encoding ATP6 and 0.45-kb RNA encoding ORF79 by endonucleolytic cleavage at a site(s) located between the coding sequences of B-atp6 and orf79 (Iwabuchi et al. 1993; Akagi et al. 1994; Wang et al. 2006). Alternatively, the B-atp6-orf79 RNA is degraded in the presence of the $R f 1 b$ gene (Wang et al. 2006). When the Rf1a and $R f 1 b$ genes are both present, the Rf1a gene has an epistatic effect over the $R f 1 b$ gene: the primary B-atp6-orf79 transcript is processed by the function of RF1A, but the RNA fragments generated by the processing are not degraded by the function of RF1B. It is hypothesized that the inability of RF1B protein to destabilize the RNA fragments processed in the presence of RF1A protein is due to the loss of the recognition sequence necessary for RF1B-dependent RNA degradation (Wang et al. 2006). It has also been reported that the processed RNAs are partially degraded, and the processed orf79 RNA, which remained after degradation, is not associated with the ribosome for translation, while the unprocessed B-atp6-orf79 RNA is translatable (Kazama et al. 2008). Thus, the accumulation of unprocessed B-atp6-orf79 RNA is crucial for BT-type CMS.

The male-sterile state of BT-type CMS was originally reported to be maintained stably by backcrossing the male-sterile plants with the T65 line (Shinjyo 1969). T65 was established from a cross between two Japanese strains in 1923, but has diverged into two subtypes T65(R) and T65(T) (also referred to as T65A and T65B, respectively [Sano et al. 1992]), which have slightly different responses to photoperiod 
(Tsai 1986, 1993). Interestingly, while T65(R) confers no ability to restore fertility against BT-type CMS, T65(T) confers a weak restoration function (Sano et al. 1992). Self-fertilization of plants obtained by a cross between the CMS line with the genotype [cms-bo]rf1/rf1, a homozygote of the $r f 1$ allele carrying the [cms-bo] cytoplasm, and T65(T) resulted in an increase in the extent of fertility, and the degree of fertility gradually increased with repeated self-fertilization (Sano et al. 1992). As a consequence, almost fully fertile plants were obtained in the $\mathrm{F}_{6}$ generation. The partial fertility (approximately $8 \%$ seed set) observed in the $\mathrm{F}_{1}$ plants was maintained by backcrossing $\mathrm{T} 65(\mathrm{~T})$ with the $\mathrm{F}_{1}$ plants.

A series of genetic experiments were done to characterize the gene(s) responsible for the partial fertility restoration. In brief, $[c m s-b o] r f 1 / r f 1 \times[\mathrm{T} 65(\mathrm{R}) \times$ $\mathrm{T} 65(\mathrm{~T})] \mathrm{F}_{1}$ resulted in 1:1 segregation of completely sterile and partially fertile plants; $[c m s-b o] r f 1 / r f 1 \times(\mathrm{T} 65(\mathrm{~T}) \times[c m s-b o] R f 1 / R f 1) \mathrm{F}_{1}$ resulted in 1:1:2 segregation of completely sterile, partially sterile, and fully fertile plants, respectively. Based on these results, the gene responsible for fertility restoration was considered to be a single dominant gene conferred by $\mathrm{T} 65(\mathrm{~T})$ and to be genetically independent of the $R f 1$ gene (Sano et al. 1992). This restorer gene was designated Instability of fertility restoration 1 (Ifr1; Sano et al. 1992). However, no attempt to address the mechanism of fertility restoration by Ifr 1 has been reported. Whether mechanisms analogous to those mediated by $R f 1$ are involved in the fertility restoration by Ifr 1 is not even known.

In this study to understand the mechanisms of partial fertility restoration by the Ifr 1 gene, we carried out a comparative analysis that focused on the transcript profile of B-atp6-orf79 using [cms-bo]rf1/rf1 plants and fertility restored plants obtained by crossing [cms-bo]rf1/rf1 plants with T65(T) carrying the Ifr 1 gene. The results indicated that fertility restoration by Ifr1 was correlated with a decrease in the unprocessed B-atp6-orf79 transcript, but via a mechanism that differed from that involved in endonucleolytic cleavage of the transcript, which is known to be caused by the $R f 1$ 
locus.

\section{Materials and methods}

Plant materials

Four rice (Oryza sativa L.) lines, [cms-bo]Rf1/Rf1, [cms-bo]rf1/rf1, T65(R), and T65(T), were used. The $[c m s-b o] R f 1 / R f 1$ line has the $[c m s-b o]$ cytoplasm derived from Chinsurah Boro II and its nuclear restoring gene $R f 1$, which were introduced into the T65(R) line from Chinsurah Boro II by successive backcrosses. A completely male-sterile line $[\mathrm{cms}-\mathrm{bo}] \mathrm{rf1} / \mathrm{rf1}$ was made by backcrossing the $[\mathrm{cms}-\mathrm{bo}] \mathrm{Rf1} / \mathrm{Rf1} \times$ T65(R) $F_{1}$ plants with T65(R). The [cms-bo]rf1/rf1 line was maintained by crossing with T65(R). Plants having partial fertility as a consequence of crossing between the male-sterile [cms-bo]rf1/rf1 line and the T65(T) line were also used. These include the $\mathrm{BC}_{7} \mathrm{~F}_{1}$ plants derived from backcrossing [cms-bo]rf1/rf1 $\times \mathrm{T} 65(\mathrm{~T}) \mathrm{F}_{1}$ plants with $\mathrm{T} 65(\mathrm{~T})$, and $\mathrm{F}_{3}$ and $\mathrm{F}_{9}$ selfed progenies of the $\mathrm{BC}_{7} \mathrm{~F}_{1}$ plants. For the $\mathrm{F}_{3}$ generation, two plant populations $\left(\mathrm{F}_{3}-1\right.$ and $\left.\mathrm{F}_{3}-2\right)$, which were independently derived from the $\mathrm{BC}_{7} \mathrm{~F}_{1}$ plants, were used.

Analysis of pollen fertility

Pollen grains were harvested from spikelets a day before anthesis and stained with iodine-potassium iodide $\left(\mathrm{I}_{2}-\mathrm{KI}\right)$ solution (Nelson 1962). For each plant line, pollen grains from 12-18 anthers of 2-3 spikelets were analyzed. Pollen fertility was estimated based on the frequency of stainable pollen grains. 
DNA extraction and Southern blot analysis

Total DNA was extracted from leaf tissues using Nucleon Phytopure (Amersham Bioscience) according to the manufacturer's instructions. Total DNA (3 $\mu \mathrm{g})$ digested with EcoRI was fractionated by electrophoresis on a $0.9 \%$ agarose gel. DNAs were transferred to nylon membranes and allowed to hybridize with a labeled probe. Hybridization, labeling of probes, washing of membranes after hybridization and detection of signals were carried out using AlkPhos Direct Labeling and Detection System (Amersham). The coding region of the atp6 gene was amplified by PCR using specific primers atp6F1 (5'-CTGAGGGGTAGAATTTGAATTCC-3') and atp6R1 (5'-TAAGGGACCAAGATCTCCTATGA-3') and used as a probe.

DNA sequence analysis

The nucleotide sequences covering the entire coding regions of the $R f 1 a$ and $R f 1 b$ genes were amplified from total DNA by PCR using specific primers designed to anneal to the 5'- and 3'-untranslated regions. The analyzed sequences contained the 782-bp 5'-upstream region and 1029-bp 3'-downstream region of the Rf1a gene, and the 45-bp $5^{\prime}$ upstream region and 449-bp $3^{\prime}$ downstream region of the $R f 1 b$ gene, in addition to the coding regions of these genes. The following primer pairs were used for PCR: for Rf1a, rf1F1 (5'-CTTGGGAGATAGGATATGGAGAGAGAA-3') and rf1R1 (5'-AAACATCTTTGGAACGCTTCTTGAG-3'); and for $R f 1 b, \quad \operatorname{rflbF} 1$ (5'-AAAAACATGCCACTCGTAGCTAGAAAAA-3') and rflbR1 (5'-GGGGAATCTTTGTCACTGCAAGTTTAGC-3'). After confirmation of the amplification of a single DNA species by gel electrophoresis, the PCR products were purified using Get pure DNA Kit-Agarose (Dojindo), then the purified fragments were sequenced using BigDye Terminator Cycle Sequencing v1.1 Ready Reaction Kit 
(Applied Biosystems) and a DNA sequencing system (ABI 3130, Applied Biosystems). DNA sequences were analyzed using the program ATGC ver. 4 (Genetyx Co.).

RNA extraction and cDNA synthesis

Total RNA from leaves of three-month-old plants and mature anthers was extracted with Trizol reagent (Invitrogen) according to the manufacturer's instructions, with the modification that we removed the genomic DNA from the RNA fraction using DNase I (Takara Bio). Total RNA $(0.5 \mu \mathrm{g})$ was used as the template for cDNA synthesis. The cDNA synthesis reaction mixture was prepared by mixing $2 \mu 1$ of $5 \times$ reaction buffer (250 mM Tris-HCl, $\mathrm{pH} 8.3 ; 375 \mathrm{mM} \mathrm{KCl}, 15 \mathrm{mM} \mathrm{MgCl}_{2}$ ), $1 \mu \mathrm{l}$ of $0.1 \mathrm{M}$ dithiothreitol (DTT), $0.25 \mu \mathrm{l}$ RNaseOUT inhibitor (Invitrogen), $1 \mu 1$ of $50 \mu \mathrm{M}$ random 9-mer primer (TaKaRa Bio), $2 \mu 1$ of $2.5 \mathrm{mM}$ dNTPs, the RNA solution, and water, to a final volume of $9.5 \mu \mathrm{l}$. After the addition of $0.5 \mu 1$ of M-MLV reverse transcriptase (Invitrogen), cDNA synthesis was done at $42^{\circ} \mathrm{C}$ for $1 \mathrm{~h}$. The reverse transcriptase was inactivated by heating the sample at $99^{\circ} \mathrm{C}$ for $1 \mathrm{~min}$.

Quantitative analyses of DNA and RNA by real-time PCR

For analyzing changes in the copy number of mitochondrial genes, we ran a quantitative PCR using $5 \mathrm{ng}$ of total DNA and SYBR Premix ExTaq Perfect Real Time (TaKaRa Bio) with the DNA Engine Opticon 2 System (MJ Research, Waltham, MA, USA). The amount of the actin gene, a single copy gene in the rice nuclear genome, was used as a control for the analysis. The PCR conditions were: 40 cycles of $95^{\circ} \mathrm{C}$ for $10 \mathrm{~s}, 60^{\circ} \mathrm{C}$ for $20 \mathrm{~s}, 72^{\circ} \mathrm{C}$ for $20 \mathrm{~s}$, and $78^{\circ} \mathrm{C}$ for $2 \mathrm{~s}$. Fluorescence was quantified before and after the incubation at $78^{\circ} \mathrm{C}$ to monitor the formation of primer-dimers. The following primer pairs were used for the PCR: for the total N-atp6 and B-atp6 genes, atp6F3 
(5'-CGAGGCCAGTTGAGATCAGT-3')

and

atp6R3

(5'-GCCCTCTCAAATGGTTCAAA-3'); for the B-atp6-orf79 genes, 2.0F1

(5'-AGGAGCCGAAGATTTTAGGG-3')

and

2.0R2

(5'-TTAGTCCCTCGGGTAGTGGA-3'); for the cox2 gene, $\operatorname{cox} 2 \mathrm{~F} 2$

(5'-TAGGATCTCAAGACGCTGCAAC-3')

and

$\operatorname{cox} 2 \mathrm{R} 2$

(5'-CGATAGTAGTTCCATGAACAATCC-3'); for the cob gene, cobF2 (5'-CTACCGATCCATGCCATTCT-3')

and

cobR2

(5'-GTTGACATCCGATCCAACCT-3'); and for the actin gene, OsRAc1-F4 (5'-TGGTGGTACCACTATGTTCCCT-3')

and

OsRAc1-R4

(5'-ACAATGGATGGGCCAGACTC-3').

For analyzing changes in the transcript levels of mitochondrial and nuclear genes, we ran a quantitative reverse transcription-mediated PCR (RT-PCR) using a 1- $\mu 1$ sample of the reaction mixture of cDNA synthesis. The mRNA level of the actin gene was used as a control for the analysis. The PCR was done as described. A reaction mixture without reverse transcriptase was used as a control to confirm that no amplification occurred from genomic DNA contamination of the RNA sample. The lack of amplification from such samples was examined by both gel electrophoresis of PCR products and real-time PCR. The following primer pairs were used for the PCR: for the Rf1a gene, Rfla-RTF7 (5'-ATTAGATCCAAAACAATTTATAGG-3') and Rfla-RTR7 (5'-ATAAGATAATCAGATCAGAAACC-3'); for the $R f 1 b$ gene, Rflb-RTF1 (5'-GCTGGGGTTTACATGTCCAA-3') and Rflb-RTR1 (5'-ATTCAGTGAGAAGGCCAACA-3'); for the orf79 gene (both processed and unprocessed transcripts of the B-atp6-orf79 genes), $0.45 \mathrm{~F} 3$ $\begin{array}{lll}\left(5^{\prime} \text {-TCTGGTCCGATGGCTCTTCTCC-3') }\right. & \text { and }\end{array}$ (5'-CCCACCACGAATAGTCAACC-3'); and for the unprocessed transcript of the B-atp6-orf79 genes, primers 2.0F1 and 2.0R1. Primers specific for the Rf1a and Rf1b genes were designed by aligning nucleotide sequences of the 10 PPR-containing genes 
at the chromosomal region of $R f 1$ with the CLUSTAL W Multiple Sequence Alignment Program version 1.8 (http://clustalw.genome.jp) (Thompson et al. 1994), and differences were detected. For the total N-atp6 and B-atp6, cox2, cob, and actin genes, the same primers used for quantitative analysis of DNA were used. In all PCR experiments, amplification of a single DNA species was confirmed by both melting curve analysis of real-time PCR and gel electrophoresis of PCR products. The data were obtained from three biological replicates except for the RT-PCR analysis of $\mathrm{F}_{9}$ plants for which we ran two replicates. Differences between plants were statistically analyzed using the Fisher's protected least significant difference (PLSD) test.

\section{Results}

Effects of the Ifr 1 gene on pollen fertility

To examine the effects of the Ifr 1 gene on pollen fertility, we harvested pollen grains before anthesis and treated them with $\mathrm{I}_{2}-\mathrm{KI}$. The ratio of stainable pollen grains produced in $[c m s-b o] R f 1 / R f 1$ and [cms-bo]rf1/rf1 plants was almost $100 \%$ and $0 \%$, respectively (Fig. 1g, h; Table 1) as reported previously (Itabashi et al. 2009). In contrast, both stainable and non-stainable pollen grains were produced in plants carrying the Ifr 1 gene, namely, $\mathrm{BC}_{7} \mathrm{~F}_{1}, \mathrm{~F}_{3}-1, \mathrm{~F}_{3}-2$ and $\mathrm{F}_{9}$ plants (Fig. 1i-1; Table 1). In addition, a considerable number of stainable pollen grains were only partially stained and only a small number of pollen grains were completely stained in these Ifr 1 carriers (Fig. 1m-o). These results are consistent with a previous observation that Ifr1 carriers have partial seed fertility (Sano et al. 1992). No differences were detected in the morphology of flower organs before anthesis between these plants (Fig. 1a-f). 
The $R f 1 a$ and $R f 1 b$ genes of the T65(T) line and the fertility restored plants are identical to those of the $\mathrm{T} 65(\mathrm{R})$ line

The BT-type CMS can be restored gametophytically by either of two closely linked genes at the $R f 1$ locus, $R f 1 a$ or $R f 1 b$ (Wang et al. 2006). Previous genetic analysis indicated that the T65(T) line carries the $r f 1$ allele (namely, $r f 1 a$ and $r f 1 b$ alleles) and that the effect of partial fertility restoration conferred by the Ifr 1 gene in the T65(T) line is independent of the $R f 1$ locus (Sano et al. 1992). To examine whether the functions of the $R f 1 a$ and $R f 1 b$ genes are involved in the process of partial fertility restoration conferred by the genetically-independent Ifr1 gene, we analyzed the nucleotide sequences of the $R f 1 a$ and $R f 1 b$ genes from the T65(T) line and fertility restored plants. For a comparison, the nucleotide sequences of the same genes in the T65(R) line, which carries the $r f 1$ allele and does not induces fertility restoration, were also analyzed. The nucleotide sequences of both the Rf1a (from 782-bp upstream of the initiation codon to 1029-bp downstream of the stop codon) and $R f 1 b$ (from 45-bp upstream of the initiation codon to 449-bp downstream of the stop codon) genes of $\mathrm{T} 65(\mathrm{~T})$ and $\mathrm{F}_{9}$ generation of the fertility restored plants were completely identical to those of the T65(R) line (data not shown; the nucleotide sequence data have been deposited in the DDBJ/EMBL/GanBank database under accession numbers AB470406-AB470409). Therefore, the presence and absence of the fertility restoration ability in T65(T) and T65(R), respectively, were not ascribed to a difference in the nucleotide sequences of the Rf1a and Rf1b genes.

The nucleotide sequence of the $R f 1 a$ gene of these plants had a premature stop codon as reported previously for the $r f 1$ allele from other rice lines (Kazama et al. 2003; Akagi et al. 2004; Komori et al. 2004; Wang et al. 2006), indicating that the gene encodes a nonfunctional protein. For the $R f 1 b$ gene, a previous analysis indicated that a base substitution resulting in an amino acid change was correlated with the loss of 
fertility-restoration function: A and $G$ residues at nucleotide position 1235 of the coding region of the $R f 1 b$ gene were commonly detected in various rice lines carrying the $R f 1 b$ and $r f 1 b$ alleles, respectively (Wang et al. 2006). Our analysis indicated that T65(R), T65(T), and fertility restored plants had a G residue at position 1235.

The mRNA levels of $R f 1 a$ and $R f 1 b$ genes are not changed in the fertility restored plants

Although the nucleotide sequences of the $R f 1 a$ and $R f 1 b$ genes of $T 65(\mathrm{~T})$ and the $\mathrm{F}_{9}$ plant were completely identical to those of $\mathrm{T} 65(\mathrm{R})$ and these genes encode proteins that are correlated with recessive genotypes, whether an increase in the level of the expression of these genes might occur and result in partial fertility restoration had not been known. To examine such a possibility, we analyzed the mRNA levels of the Rf1a and $R f 1 b$ genes in anther tissues by quantitative RT-PCR. No significant difference in the mRNA level of the Rf1a gene was detected between the fertility restored plants, namely, $\mathrm{BC}_{7} \mathrm{~F}_{1}, \mathrm{~F}_{3}-1, \mathrm{~F}_{3}-2$ and $\mathrm{F}_{9}$ plants, and the CMS line carrying the rf1 allele derived from the T65(R) line (Fig. 2a). This analysis also revealed that the mRNA levels of the Rf1a gene in these plants were approximately 50 times lower than that in plants carrying the dominant $R f 1$ allele (Fig. 2a). The lower mRNA level can be due to the destabilization of mRNA caused by a base substitution that led to premature termination of translation, which is known as nonsense-mediated mRNA decay (reviewed by Maquat, 2004). The mRNA level for the $R f 1 b$ gene did not differ significantly among any of the plants analyzed (Fig. 2b). These results indicate that the partial restoration of fertility conferred by the Ifr 1 gene of T65(T) can be attributed to neither a change in nucleotide sequences of the Rf1a or $R f 1 b$ genes nor a change in the mRNA level of these genes.

The DNA amount of B-atp6-orf79 in the fertility restored plants is unchanged 
In common bean, a decrease in the copy number of a mitochondrial subgenomic DNA molecule, on which the pvs-orf239 genes responsible for CMS is located, is associated with restoration from the CMS phenotype by the fertility restorer gene in the nuclear genome (Janska et al. 1998). To examine whether the observed reduction in the level of unprocessed B-atp6-orf79 transcript in the fertility restored plants is accompanied by a change in the amount of mtDNA molecule on which the B-atp6-orf79 genes are located, we ran a Southern blot analysis and real-time PCR analysis. The mtDNA fragments that contain the N-atp6 and B-atp6-orf79 genes could be distinguished by Southern blot analysis of the EcoRI-digested leaf DNA with a probe specific to the atp6 gene: the probe hybridized 2.1-kb and 1.5-kb fragments containing the $\mathrm{N}$-atp6 and B-atp6-orf79 genes, respectively, as reported previously (Kadowaki and Harada 1989; Kadowaki et al. 1990; Iwabuchi et al. 1993). The intensity of the hybridization signals of N-atp6 and B-atp6 appeared very similar to each other, and no changes in relative intensities between these signals were detected between CMS line and any of the restored plants (data not shown).

The amount of genes located on the mitochondrial genome was also analyzed by quantitative PCR using the actin gene, a single copy gene encoded by the nuclear genome, as an internal control. No significant differences in the amount of B-atp6-orf79, total atp6, cox2, and cob genes were detected between the CMS line and the restored plants in leaf tissues (Fig. 3). In anther tissues, differences were detected only between limited plants: between $\mathrm{F}_{3}-1$ and $\mathrm{F}_{3}-2$ plants in the amount of total atp6; between [cms-bo]Rf1/Rf1 and $\mathrm{F}_{3}-1$ plants and between $\mathrm{F}_{3}-1$ and $\mathrm{F}_{3}-2$ plants in the amount of cox2. There was no difference in the amount of B-atp6-orf79 and cob between any of these plants in anther tissues. These results indicate that no quantitative change associated with the fertility restoration has occurred in the mtDNA. 
The processing efficiency of the B-atp6-orf79 transcript in fertility restored plants was as low as that in the CMS line

To examine whether the B-atp6-orf79 primary transcript is cleaved at a site(s) between B-atp6 and orf79 in fertility restored plants obtained by crossing [cms-bo]rf1/rf1 plants with T65(T) carrying the Ifr 1 gene, we performed quantitative RT-PCR. Two primer sets were designed, one amplifying the orf79 region from both processed and unprocessed RNA, the other amplifying the region that encompasses the processing site from the RNA that remained unprocessed (Fig. 4a). The processing efficiency of the transcript of B-atp6-orf79 was calculated by the relative amount of RNA containing the processing site (corresponding to unprocessed B-atp6-orf79 RNA) vs. the orf79 RNA.

The relative amounts of unprocessed RNA vs. orf79 RNA in both the leaf and anther tissues were lower in the $[c m s-b o] R f 1 / R f 1$ line than in the $[c m s-b o] r f 1 / r f 1$ line (Fig. 4b). These results indicate that processing at the site occurred more efficiently in the $[c m s-b o] R f 1 / R f 1$ line, as reported previously based on a Northern blot analysis (Iwabuchi et al. 1993). The relative amounts of unprocessed RNA vs. orf79 transcripts in the fertility restored plants, $\mathrm{BC}_{7} \mathrm{~F}_{1}, \mathrm{~F}_{3}-1, \mathrm{~F}_{3}-2$ and $\mathrm{F}_{9}$, were similar to those in the [cms-bo]rf1/rf1 line, and a statistically significant difference was detected only between the $[c m s-b o] r f 1 / r f 1$ line and $\mathrm{F}_{3}-1$ plants in anther tissues, for which the ratio was rather higher in the $\mathrm{F}_{3}-1$ (Fig. 4b). These results indicate that an increase in the efficiency of the processing of the B-atp6-orf79 primary transcripts was not involved in the restoration of fertility in the restored plants.

The cellular level of unprocessed RNA is reduced in the fertility restored plants

Although no increase in the efficiency of RNA processing was detected, there still remained a possibility that the absolute level of unprocessed B-atp6-orf79 RNA per cell 
might have changed in the restored plants. Therefore, the mean level of unprocessed RNA per cell was evaluated using the ratio of the level of unprocessed B-atp6-orf79 RNA to the mRNA level of the actin gene encoded in the nuclear genome.

The relative amount of unprocessed B-atp6-orf79 RNA vs. actin mRNA in [cms-bo]Rf1/Rf1 plants was lower than that in [cms-bo]rf1/rf1 plants as expected (Fig. 5a). In fertility restored plants, $\mathrm{BC}_{7} \mathrm{~F}_{1}, \mathrm{~F}_{3}-1, \mathrm{~F}_{3}-2$ and $\mathrm{F}_{9}$, the relative amounts of unprocessed B-atp6-orf79 RNA vs. actin mRNA were also significantly lower than those in $[c m s-b o] r f 1 / r f 1$ in both leaf and anther tissues (Fig. 5a). Similarly, the relative amounts of orf79 RNA vs. actin mRNA in fertility restored plants were lower than those in [cms-bo]rf1/rf1 plants (data not shown). These results indicate that the fertility restoration by $R f 1$ and that by Ifr 1 were both correlated with a decrease in the level of unprocessed B-atp6-orf79 transcript, although the efficient processing of the B-atp6-orf79 primary transcript was involved in the fertility restoration by $R f 1$ but not in that by Ifr1 (Fig. 4b). The total levels of N-atp6 and B-atp6 RNA in the [cms-bo]rf1/rf1 and the fertility restored plants did not differ significantly (Fig. 5b), indicating that the decrease in the level of unprocessed B-atp6-orf79 RNA in the presence of Ifr1 was not accompanied by a change in the total level of atp6 RNA.

The transcript levels of two unlinked genes, cox2 and cob, were also analyzed. No significant difference in the level of cox2 was detected in anther tissues between [cms-bo]rf1/rf1 and any of the fertility restored plants, although differences in the leaf tissues were detected between [cms-bo]rf1/rf1 and $\mathrm{BC}_{7} \mathrm{~F}_{1}, \mathrm{~F}_{3}-2$, and $\mathrm{F}_{9}$ plants (Fig. 5c). Similarly, no significant difference in the level of cob was detected between [cms-bo]rf1/rf1 and fertility restored plants except for between anther tissues of [cms-bo]rf1/rf1 and $\mathrm{F}_{3}-2$ plants (Fig. 5d). The cause of the difference between fertility restored plants is not known at present. It might reflect slight fluctuation of gene expression level as a consequence of hybridization between different plant lines and/or subsequent self-fertilization. In any case, these results suggest that changes in the 
transcript levels of atp6, cox2, and $c o b$ are not necessary to restore fertility in the presence of Ifr1, while changes in the level of unprocessed B-atp6-orf79 transcript are unequivocally correlated with the process.

\section{Discussion}

CMS has been attributed to chimeric ORFs present in the mitochondrial genomes in many plants (Hanson and Bentolila 2004). The unique proteins encoded by these ORFs were associated with the dysfunction of the mitochondria as well as the consequent male-sterility. In the BT-type CMS of rice, the chimeric gene orf79 is present downstream of B-atp6 and is thought to cause male-sterility due to the toxicity of the encoded protein. A high level of unprocessed B-atp6-orf79 RNA is associated with the CMS phenotype (Iwabuchi et al. 1993; Akagi et al. 1994), and the restoration of fertility was associated with a decrease in the level of unprocessed B-atp6-orf79 RNA through a mechanism involving the processing or degradation of the transcript (Iwabuchi et al. 1993; Akagi et al. 1994; Wang et al. 2006). A previous report also indicated that overexpression of orf79, which is fused to the nucleotide sequence encoding the mitochondrial transit peptide, caused a decrease in the extent of male fertility (Wang et al. 2006). Accordingly, the decrease in the level of unprocessed RNA in the fertility restored plants observed in this study could account for their partial restoration of fertility. The fact that unprocessed B-atp6-orf79 transcript levels in all the Ifr1 carriers were higher and lower than those in $R f 1$ and $r f 1$ homozygotes, respectively, in anther tissues (Fig. 5a) is consistent with the partial restoration by Ifr1.

Because there was no difference in the level of unprocessed B-atp6-orf79 RNA relative to orf79 RNA between the CMS plants and the fertility restored plants, the 
possibility that $R f 1 a$, whose effect on the B-atp6-orf79 locus is to cleave the transcript at an internal position between B-atp6 and orf79, is involved in the fertility restoration by Ifr 1 should be excluded. The nucleotide sequence of the $R f 1 a$ gene in T65(T) and in a fertility restored plant $\left(\mathrm{F}_{9}\right)$ was identical to that of the maintainer line $\mathrm{T} 65(\mathrm{R})$ and contained a premature stop codon, which confers no fertility restoration to CMS plants. In addition, the mRNA level of Rf1a in the fertility restored plants was as low as that in the [cms-bo]rf1/rf1 plants. These facts are consistent with the notion that $R f 1 a$ is not the factor involved in the fertility restoration by Ifr1. Similarly, the present results indicated that neither a change in nucleotide sequence nor a change in the mRNA level of $R f 1 b$ accounts for the fertility restoration by Ifr 1 . The remaining possibility for the involvement of $R f 1 b$ in this phenomenon may be that the level of RF1B protein and/or its activity is modulated by the presence of Ifr1, which might result in the reduction of unprocessed B-atp6-orf79 transcript. It is also possible that other PPR protein gene(s) in the region adjacent to the $R f 1 a$ or $R f 1 b$ genes or in the other regions of the genome is activated by Ifr1, although the functions of these genes are uncharacterized. It is not likely that the Ifr1 gene is involved in the regulation of mtDNA copy number and/or rearrangement that results in quantitative changes in mtDNA because no difference in the copy number of mitochondrial genes was detected between the CMS line and fertility restored plants. Overall, the decrease in the level of unprocessed RNA per cell without any change in the efficiency of RNA processing or the quantity of mtDNA suggests that either transcription rate or stability of the transcripts of B-atp6-orf79 was reduced in the restored plants. The Ifr 1 gene is likely to encode a novel protein that brings about such changes in mitochondria directly or indirectly.

A gradual increase in the extent of fertility with an increase in the number of self-fertilizations of the hybrids between [cms-bo]rf1/rf1 and T65(T) was detected previously (Sano et al. 1992). In addition, the high level of fertility observed in the $\mathrm{F}_{10}$ generation reverted to a low level through recurrent backcrossing with T65(T) plants 
(Sano et al. 1992). Although the present results indicated that the fertility restoration by Ifr1 was correlated with a decrease in the unprocessed B-atp6-orf79 transcript, no prominent difference in the level of the unprocessed RNA was detected between different generations of the fertility restored plants. In this context, it is tempting to speculate that certain epigenetic changes in the nuclear-encoded gene(s) that slightly affect fertility might accumulate with recurrent self-fertilization. In addition, although the frequency of stainable pollen grains in the Ifr 1 carriers was higher than that in [cms-bo]rf1/rf1 plants, no increase in stainable pollen grains was observed with an increase in the number of self-fertilizations. Accordingly, we tentatively assume that Ifr1 may act not only on gametogenesis but also on a process after gametogenesis (e.g., anthesis). Such possibilities, as well as the lack of strong correlation between the increase in the level of fertility and the level of unprocessed B-atp6-orf79 RNA, still need to be examined.

CMS can function as a mechanism of reproductive isolation in plants (Koide et al. 2008). A previous analysis of the distribution of genes that restore BT-type CMS among various rice strains indicated that $13 \%$ of examined strains functioned in partial fertility restoration (Shinjyo 1975) like that conferred by Ifr1. A recent report also indicated the presence of rice strains carrying $R f$ genes that confer fertility restoration of various degrees (Tan et al. 2008). It is possible that some of these strains have genes similar to Ifr1, although their genetic relationships are unknown. The presence of Ifr1, in addition to $R f 1$, indicates that multiple factors are involved in fertility restoration of BT-type CMS and have been harbored redundantly in the rice genome, allowing the maintenance of interfertile relationships during rice evolution.

\section{Acknowledgements}

We thank Hironori Nagano for technical help with the sequencing analysis of the rice $R f$ 
genes. We also thank Kazumitsu Onishi and Yohei Koide for valuable suggestion. This work was supported in part by grants from the Ministry of Education, Culture, Sports, Science and Technology of Japan.

\section{References}

Akagi H, Sakamoto M, Shinjyo C, Shimada H, Fujimura T (1994) A unique sequence located downstream from the rice mitochondrial atp6 may cause male sterility. Curr Genet 25:52-58

Akagi H, Nakamura A, Yokozeki-Misono Y, Imagaki A, Takahashi H, Mori K, Fujimura T (2004) Positional cloning of the rice $R f-1$ gene, a restorer of BT-type cytoplasmic male sterility that encodes a mitochondria-targeting PPR protein. Theor Appl Genet 108:1449-1457

Bentolila S, Alfonso AA, Hanson MR (2002) A pentatricopeptide repeat-containing gene restores fertility to cytoplasmic male-sterile plant. Proc Natl Acad Sci USA 99:10887-10892

Brown GG, Formanova N, Jin H, Wargachuk R, Dendy C, Patil P, Laforest M, Zhang J, Cheung WY, Landy BS (2003) The radish Rfo restorer gene of Ogura cytoplasmic male sterility encodes a protein with multiple pentatricopeptide repeats. Plant J $35: 262-272$

Chase CD (2007) Cytoplasmic male sterility: a window to the world of plant mitochondrial-nuclear interactions. Trends Genet 23:81-90

Cui X, Wise RP, Schnable PS (1996) The rf2 nuclear restorer gene of male-sterile T-cytoplasm maize. Science 272:1334-1336

Desloire S, Gherbi H, Laloui W, Marhadour S, Clouet V, Cattolico L, Falentin C, Giancola S, Renard M, Budar F, Small I, Caboche M, Delourme R, Bendahmane A 
(2003) Identification of the fertility restoration locus, $R f o$, in radish, as a member of the pentatricopeptide-repeat protein family. EMBO Rep 4:588-594

Hanson MR (1991) Plant mitochondrial mutations and male sterility. Annu Rev Genet $25: 461-486$

Hanson MR, Bentolila S (2004) Interactions of mitochondrial and nuclear genes that affect male gametophyte development. Plant Cell 16:S154-169

Itabashi E, Kazama T, Toriyama K (2009) Characterization of cytoplasmic male sterility of rice with Lead Rice cytoplasm in comparison with that with Chinsurah Boro II cytoplasm. Plant Cell Rep 28:233-239

Iwabuchi M, Kyozuka J, Shimamoto K (1993) Processing followed by complete editing of an altered mitochondrial atp6 RNA restores fertility of cytoplasmic male sterile rice. EMBO J 12:1437-1446

Janska H, Sarria R, Woloszynska M, Arrieta-Monteil M, Mackenzie SA (1998) Stoichiometric shifts in the common bean mitochondrial genome leading to male sterility and spontaneous reversion to fertility. Plant Cell 10:1163-1180

Kadowaki K, Harada K (1989) Differential organization of mitochondrial genes in rice with normal and male-sterile cytoplasms. Japan J Breed 39:179-186

Kadowaki K, Suzuki T, Kazama S (1990) A chimeric gene containing the 5' portion of atp6 is associated with cytoplasmic male-sterility of rice. Mol Gen Genet 224:10-16

Kazama T, Toriyama K (2003) A pentatricopeptide repeat-containing gene that promotes the processing of aberrant atp6 RNA of cytoplasmic male-sterile rice. FEBS Let 544:99-102

Kazama T, Nakamura T, Watanabe M, Sugita M, Toriyama K (2008) Suppression mechanism of mitochondrial ORF79 accumulation by Rf1 protein in BT-type cytoplasmic male sterile rice. Plant J 55:619-628

Klein RR, Klein PE, Mullet JE, Minx P, Roomey WL, Schertz KF (2005) Fertility restorer locus $R f 1$ of sorghum (Sorghum bicolor L.) encodes a pentatricopeptide 
repeat protein not present in the collinear region of rice chromosome 12 . Theor Appl Genet 111:994-1012

Koide Y, Onishi K, Kanazawa A, Sano Y (2008) Genetics of speciation in rice. In: Hirano H-Y, Hirai A, Sano Y, Sasaki T (ed) Rice biology in the genomics era. Springer-Verlag, pp 247-259.

Koizuka N, Imai R, Fujimoto H, Hayakawa T, Kimura Y, Kohno-Murase J, Sasaki T, Kawasaki S, Imamura J (2003) Genetic characterization of a pentatricopeptide repeat protein gene, orf687, that restores fertility in the cytoplasmic male-sterile Kosena radish. Plant J 34:407-415

Komori T, Ohta S, Murai N, Takakura Y, Kuraya Y, Suzuki S, Hiei Y, Imasaki H, Nitta $\mathrm{N}$ (2004) Map-based cloning of a fertility restorer gene, $R f-1$, in rice (Oryza sativa L.). Plant J 37:315-325

Laser KD, Lersten NR (1972) Anatomy and cytology of microsporogenesis in cytoplasmic male sterile angiosperms. Bot Rev 38:425-454

Levings III CS, Brown GG (1989) Molecular biology of plant mitochondria. Cell $56: 171-179$

Lurin C, Andrés C, Aubourg S, Bellaoui M, Bitton F, Bruyère C, Caboche M, Debast C, Gualberto J, Hoffmann B, Lecharny A, Le Ret M, Martin-Magniette ML, Mireau H, Peeters N, Renou JP, Szurek B, Taconnat L, Small I (2004) Genome-wide analysis of Arabidopsis pentatricopeptide repeat proteins reveals their essential role in organelle biogenesis. Plant Cell 16:2089-2103

Maquat LE (2004) Nonsense-mediated mRNA decay: splicing, translation and mRNP dynamics. Nat Rev Mol Cell Biol 5:89-99

Nakamura T, Sugita M (2008) A conserved DYW domain of the pentatricopeptide repeat protein possesses a novel endoribonuclease activity. FEBS Lett $582: 4163-4168$

Nelson OE (1962) The waxy locus in maize. I. Intralocus recombination frequency 
estimates by pollen and by conventional analyses. Genetics 47:737-742

Newton KJ (1988) Plant mitochondrial genomes: organization, expression and variation. Ann Rev Plant Physiol Plant Mol Biol 39:503-532

Okuda K, Chateigner-Boutin AL, Nakamura T, Delannoy E, Sugita M, Myouga F, Motohashi R, Shinozaki K, Small I, Shikanai T (2009) Pentatricopeptide repeat proteins with the DYW motif have distinct molecular functions in RNA editing and RNA cleavage in Arabidopsis chloroplasts. Plant Cell 21:146-156

Pring DR, Lonsdale DM (1985) Molecular biology of higher plant mitochondrial DNA. Int Rev Cytol 97:1-46

Sandhu APS, Abdelnoor RV, Mackenzie SA (2007) Transgenic induction of mitochondrial rearrangements for cytoplasmic male sterility in crop plants. Proc Natl Acad Sci USA 104:1766-1770

Sano Y, Eiguchi M, Hirano H-Y, Yamada M (1992) A nuclear gene modifying instability of fertility restoration in cytoplasmic male sterile rice. Genet Res, Camb 60:195-200

Schmitz-Linneweber C, Small I (2008) Pentatricopeptide repeat proteins: a socket set for organelle gene expression. Trends Plant Sci 13:663-670

Shedge V, Arrieta-Montiel M, Christensen AC, Mackenzie SA (2007) Plant mitochondrial recombination surveillance requires unusual $\operatorname{RecA}$ and MutS homologs. Plant Cell 19:1251-1264

Shinjyo C (1969) Cytoplasmic genetic male sterility in cultivated rice, Oryza sativa L. II. The inheritance of male sterility. Jpn J Genet 44:149-156

Shinjyo C (1975) Genetical studies of cytoplasmic male sterility and fertility restoration in rice, Oryza sativa L. Bull College Agric, Univ Ryukyu 22:1-57

Shinjyo C (1984) Cytoplasmic male sterility and fertility restoration in rice having genome A. In: Tsunoda S, Takahashi N (ed) Biology of rice. Japan Sci Soc Press, Tokyo, pp 321-338 
Small ID, Peeters N (2000) The PPR motif - a TPR-related motif prevalent in plant organellar proteins. Trends Biochem Sci 25:46-47

Tan YP, Li SQ, Wang L, Liu G, Hu J, Zhu YG (2008) Genetic analysis of fertility-restorer genes in rice. Biologia Plantarum 52:469-474

Thompson JD, Higgins DG, Gibson TJ (1994) CLUSTAL W: improving the sensitivity of progressive multiple sequence alignment through sequence weighting, positions-specific gap penalties and weight matrix choice. Nucl Acids Res $22: 4673-4680$

Tsai KH (1986) Possible genic differences between two T65 strains, one preserved at Taichung and the other from Ryukyu. Rice Genet Newslett 3:75-76

Tsai KH (1993) A gene accelerating the heading of late lines with ef-1 alleles. Rice Genet Newslett 10:83-84

Wang Z, Zou Y, Li X, Zhang Q, Chen L, Wu H, Su D, Chen Y, Guo J, Luo D, Long Y, Zhong Y, Liu Y (2006) Cytoplasmic male sterility of rice with Boro II cytoplasm is caused by a cytotoxic peptide and is restored by two related PPR motif genes via distinct modes of mRNA silencing. Plant Cell 18:676-687 


\section{Legends of figures}

Fig. 1 Flower morphology and pollen grains of fertile, male sterile, and fertility restored rice plants. a-f Morphology of flower organs before anthesis. Flowers of [cms-bo]Rf1/Rf1, [cms-bo]rf1/rf1, $\mathrm{BC}_{7} \mathrm{~F}_{1}, \mathrm{~F}_{3}-1, \mathrm{~F}_{3}-2$, and $\mathrm{F}_{9}$ plants are shown. A scale bar denotes $1 \mathrm{~mm}$. g-l Population of pollen grains produced in plants listed in panel a-f. Pollen grains were harvested from spikelets a day before anthesis and treated with $\mathrm{I}_{2}-\mathrm{KI}$. A scale bar denotes $100 \mu \mathrm{m}$. m-o Pollen grains with a different degree of staining in Ifr 1 carrier $\left(\mathrm{F}_{3}-2\right)$ : completely stained pollen $(\mathbf{m})$; non-stainable pollen $(\mathbf{n})$; partially stained pollens (o). A scale bar denotes $40 \mu \mathrm{m}$.

Fig. 2 Comparison of the mRNA levels of $R f 1 a$ and $R f 1 b$ genes in the CMS line and fertility restored plants. The $R f 1 a$ (a) and $R f 1 b$ (b) mRNA levels relative to the actin mRNA level in anther tissues were assessed by quantitative RT-PCR for the following plants: [cms-bo]Rf1/Rf1, [cms-bo]rf1/rf1, $\mathrm{BC}_{7} \mathrm{~F}_{1}, \mathrm{~F}_{3}-1, \mathrm{~F}_{3}-2$, and $\mathrm{F}_{9}$ plants. The $R f 1 a$ and $R f 1 b$ mRNA levels relative to the actin mRNA level in [cms-bo]rf1/rf1 plants were assigned a value of 1 . Data are means \pm SE. Statistic analysis was done using Fisher's PLSD test. Means that are not indicated by the same letter are significantly different $(P$ $<0.01)$.

Fig. 3 Comparison of the amount of B-atp6-orf79, total B-atp6 and N-atp6, cox2, and $c o b$ DNA in the CMS line and restored plants. The B-atp6-orf79 (a), total B-atp6 and N-atp6 (b), cox2 (c), and cob (d). DNA levels relative to the actin DNA level in leaf (black bars) and anther (gray bars) tissues were assessed by quantitative PCR for the following plants: $[\mathrm{cms}-\mathrm{bo}] \mathrm{R} f 1 / \mathrm{Rf} 1,[\mathrm{cms}-\mathrm{bo}] r f 1 / r f 1, \mathrm{BC}_{7} \mathrm{~F}_{1}, \mathrm{~F}_{3}-1, \mathrm{~F}_{3}-2$, and $\mathrm{F}_{9}$ plants. The DNA levels of the analyzed genes relative to the actin DNA level in [cms-bo]rf1/rf1 plants were assigned a value of 1 . Data are means \pm SE. Statistic analyses of leaf DNA 
and anther DNA were done independently using Fisher's PLSD test. Means that are not indicated by the same letter are significantly different $(P<0.05)$. Note that there was no significant difference between plants in the levels of any of the genes analyzed in leaf tissues and those of B-atp6-orf79 and cob in anther tissues.

Fig. 4 Analysis of the processing efficiency of B-atp6-orf79 transcript. a Structure of mtDNA region containing B-atp6 and orf79. The coding regions of B-atp6 and orf79 are indicated by boxes. The DNA regions common to B-atp6 and N-atp6 and present in the B-atp6-orf79 locus but not in the N-atp6 locus are indicated by a black line and a broken line, respectively. The site of processing for cleaving the primary transcript is indicated by a vertical triangle. Positions of primers for RT-PCR are indicated by horizontal arrows. PCR using primers 2.0F1 and 2.0R1 amplifies the region encompassing the processing site from unprocessed B-atp6-orf79 RNA but does not amplify the region from processed RNA. PCR using primers $0.45 \mathrm{~F} 3$ and $0.45 \mathrm{R} 3$ amplifies the orf79 region from both unprocessed and processed RNA. b Comparison of the processing efficiency of B-atp6-orf79 RNA in the CMS line and restored plants. The levels of unprocessed B-atp6-orf79 RNA relative to the orf79 RNA level in leaf (black bars) and anther (gray bars) tissues were assessed by quantitative RT-PCR for the following plants: [cms-bo]Rf1/Rf1, [cms-bo]rf1/rf1, $\mathrm{BC}_{7} \mathrm{~F}_{1}, \mathrm{~F}_{3}-1, \mathrm{~F}_{3}-2$, and $\mathrm{F}_{9}$ plants. The unprocessed B-atp6-orf79 RNA level relative to the orf79 RNA level in $[c m s-b o] r f 1 / r f 1$ plants was assigned a value of 1 . Data are means \pm SE. Statistic analyses of leaf RNA and anther RNA were done independently using Fisher's PLSD test. Means that are not indicated by the same letter are significantly different $(P<$ $0.05)$.

Fig. 5 Comparison of the mean cellular levels of unprocessed B-atp6-orf79, total B-atp6 and N-atp6, cox2, and cob RNA in the CMS line and restored plants. The 
unprocessed B-atp6-orf79 (a), total B-atp6 and N-atp6 (b), cox2 (c), and cob (d) RNA levels relative to the actin mRNA level in leaf (black bars) and anther (gray bars) tissues were assessed by quantitative RT-PCR for the following plants: [cms-bo]Rf1/Rf1, [cms-bo]rf1/rf1, $\mathrm{BC}_{7} \mathrm{~F}_{1}, \mathrm{~F}_{3}-1, \mathrm{~F}_{3}-2$, and $\mathrm{F}_{9}$ plants. The RNA levels of the analyzed genes relative to the actin mRNA level in [cms-bo]rf1/rf1 plants were assigned a value of 1 . Data are means \pm SE. Statistic analyses of leaf RNA and anther RNA were done independently using Fisher's PLSD test. Means that are not indicated by the same letter are significantly different $(P<0.05)$ in each panel. Note that the level of unprocessed B-atp6-orf79 RNA is significantly lower in all restored plants than in [cms-bo]rf1/rf1 in both leaf and anther tissues. There was no significant difference between plants in the levels of $c o b$ in leaf tissues. 
Figure 1

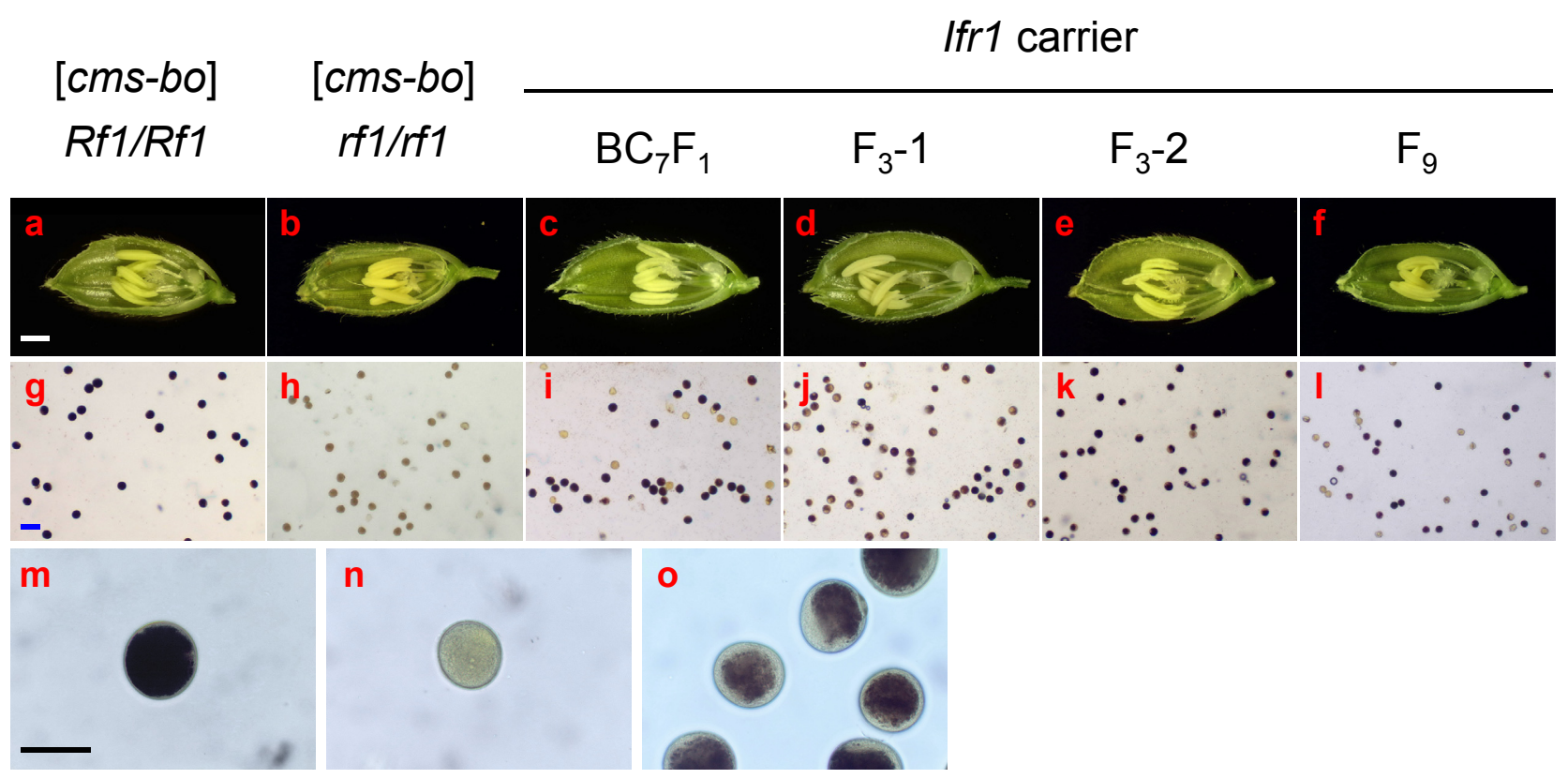


Figure 2
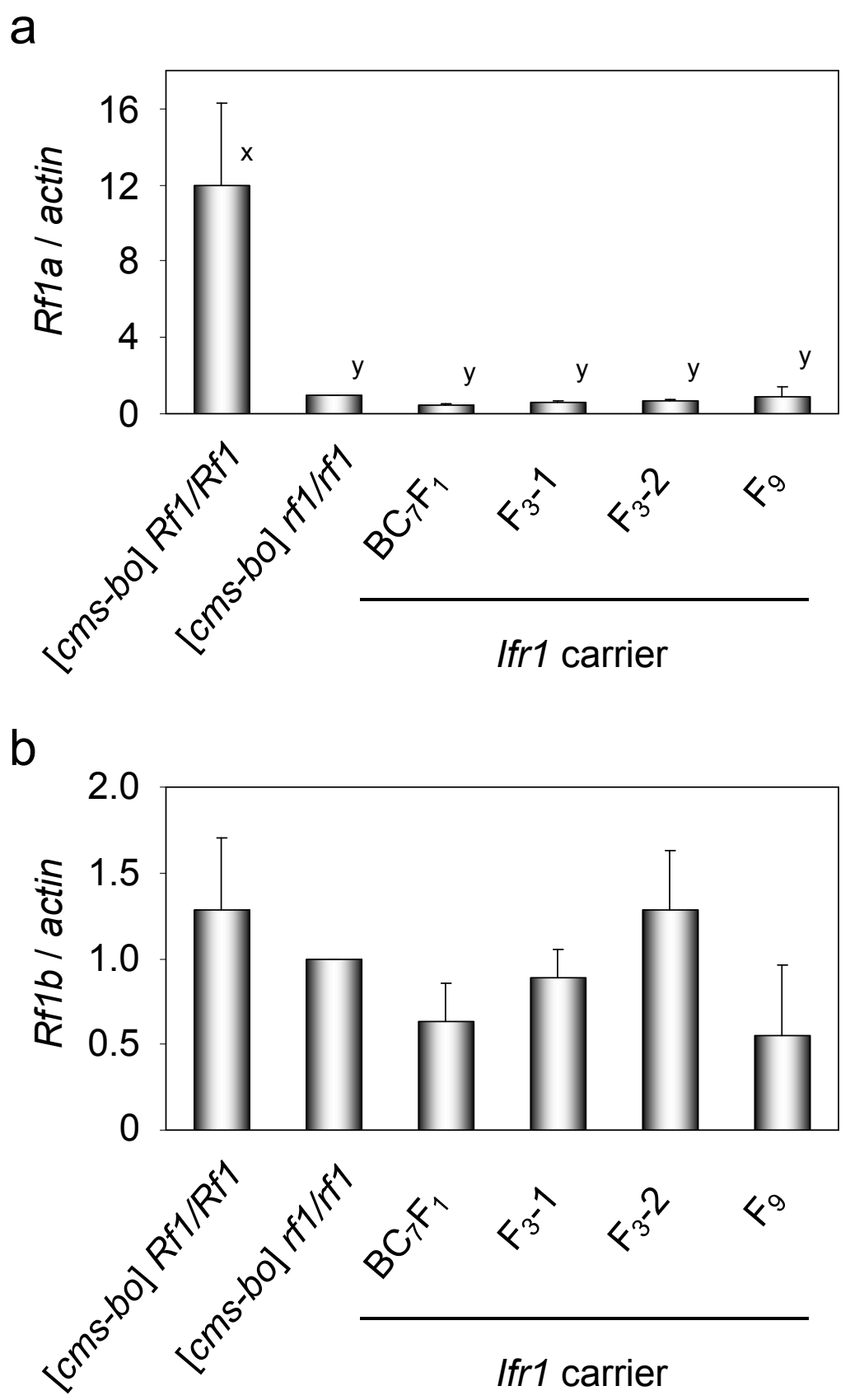
Figure 3

a

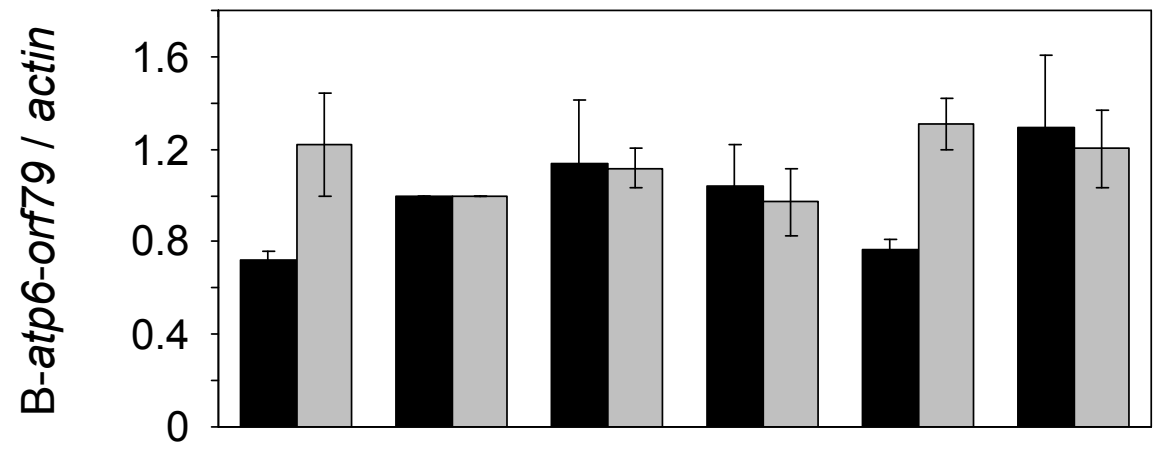

b

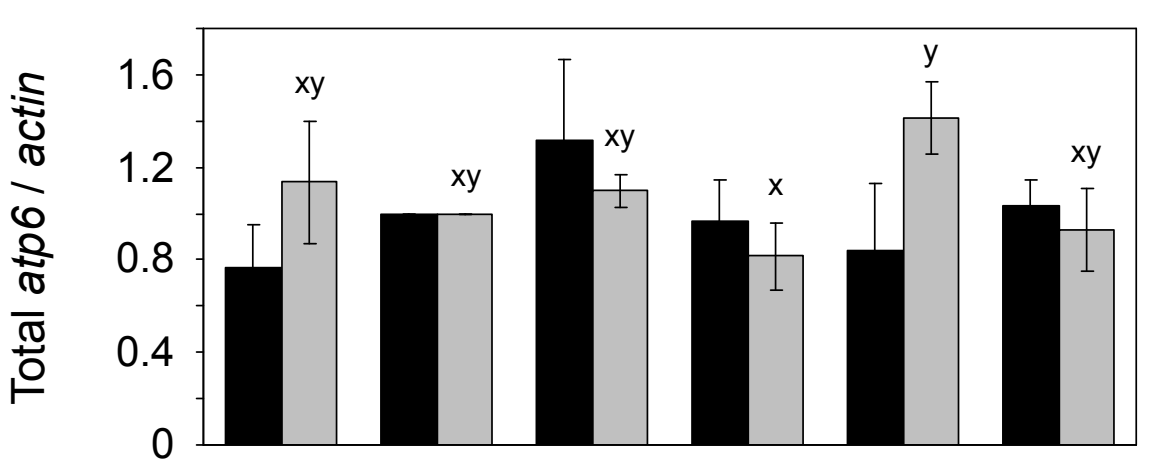

C

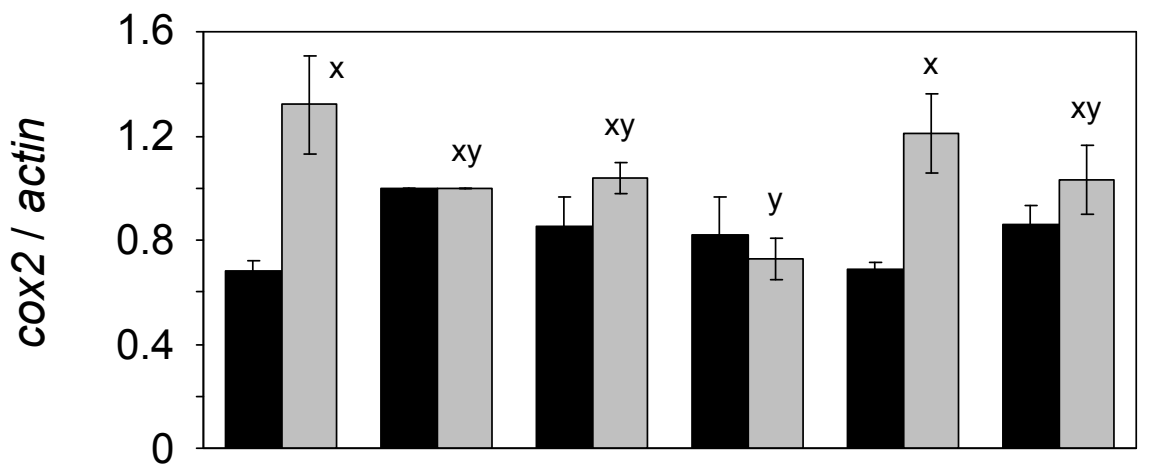

d

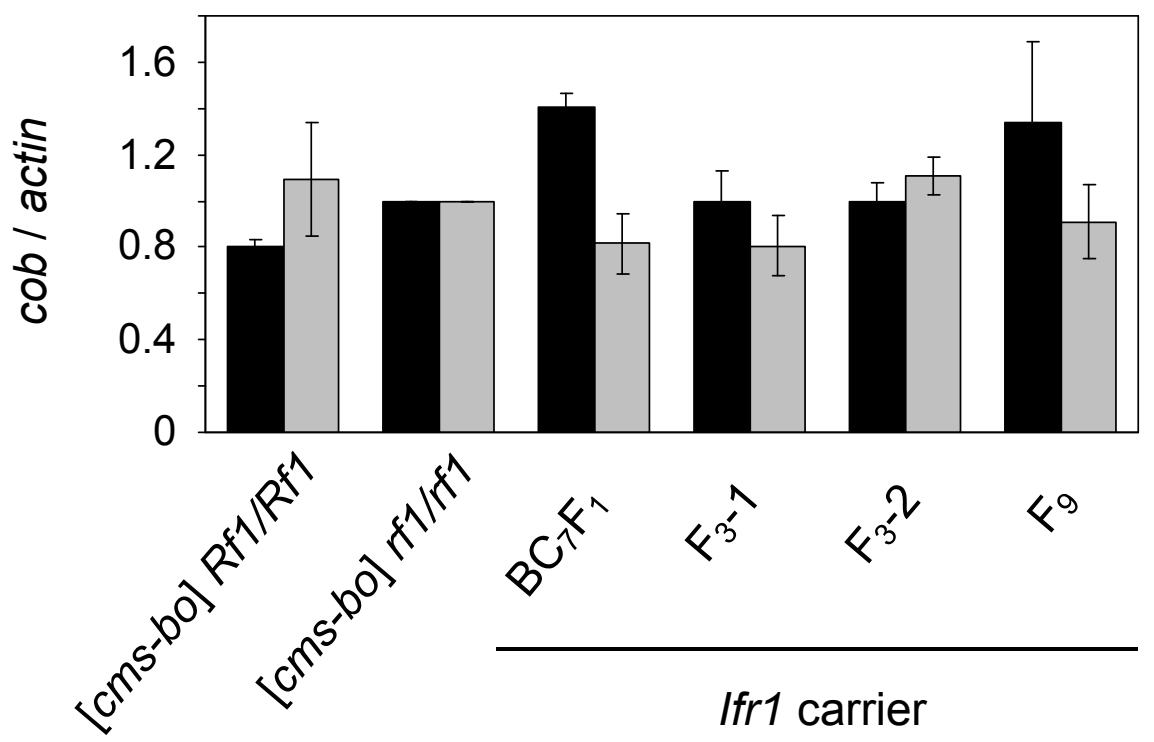


Figure 4

a

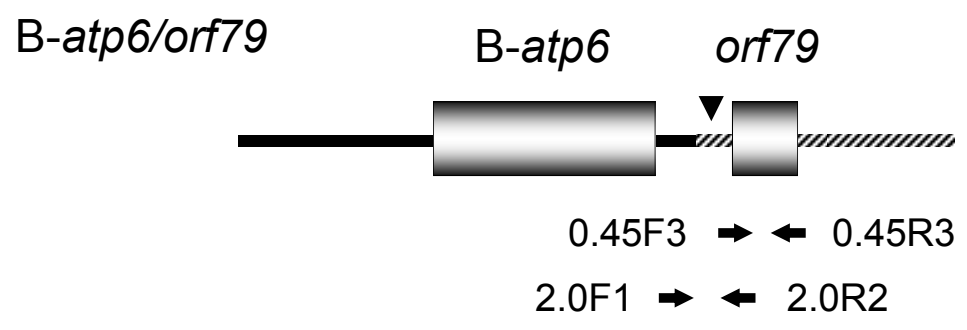

Unprocessed RNA

RF1A $\downarrow$

Processed RNA

b

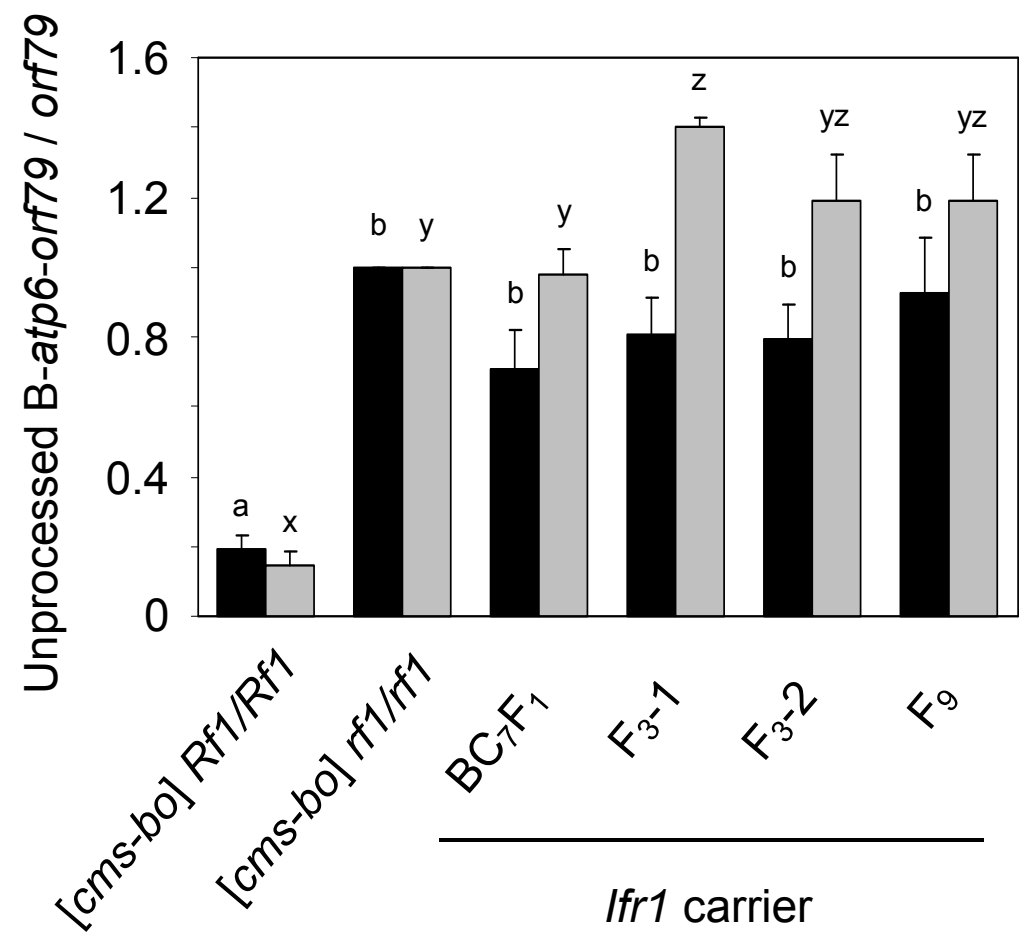


Figure 5

a

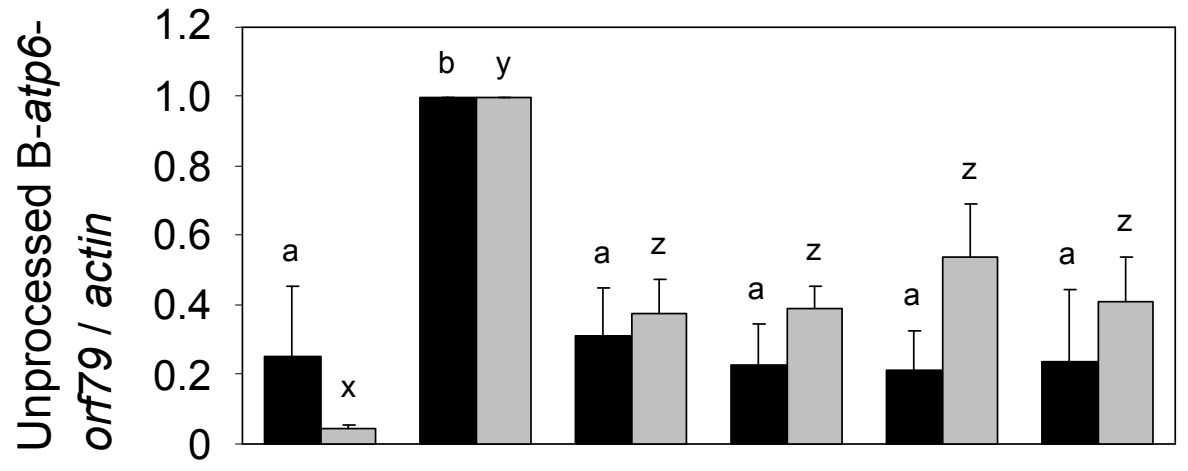

b

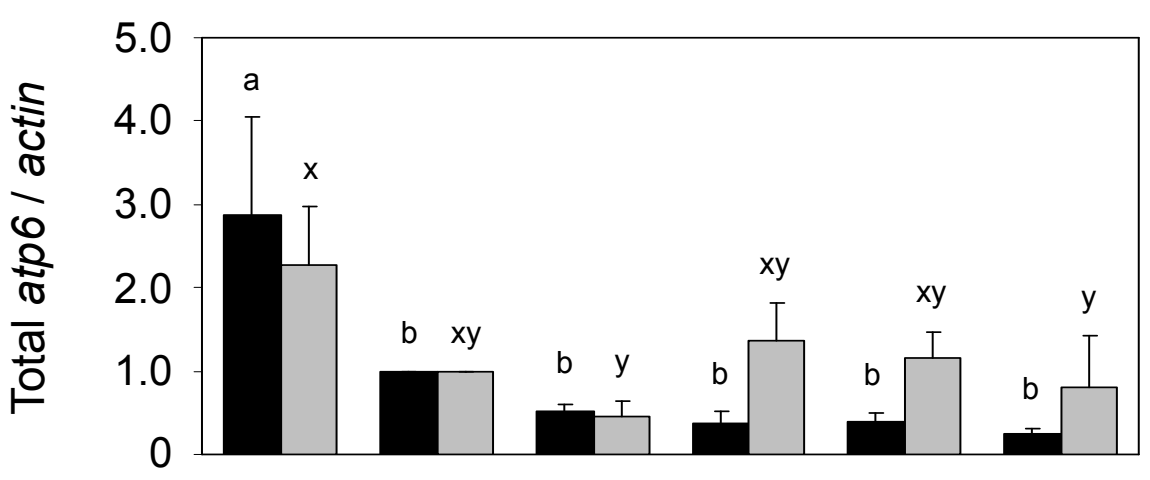

C

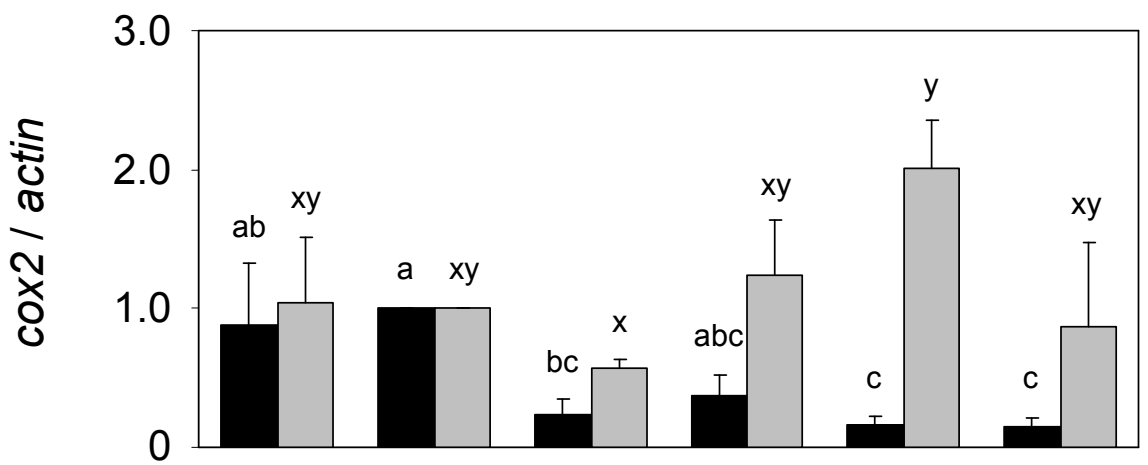

d

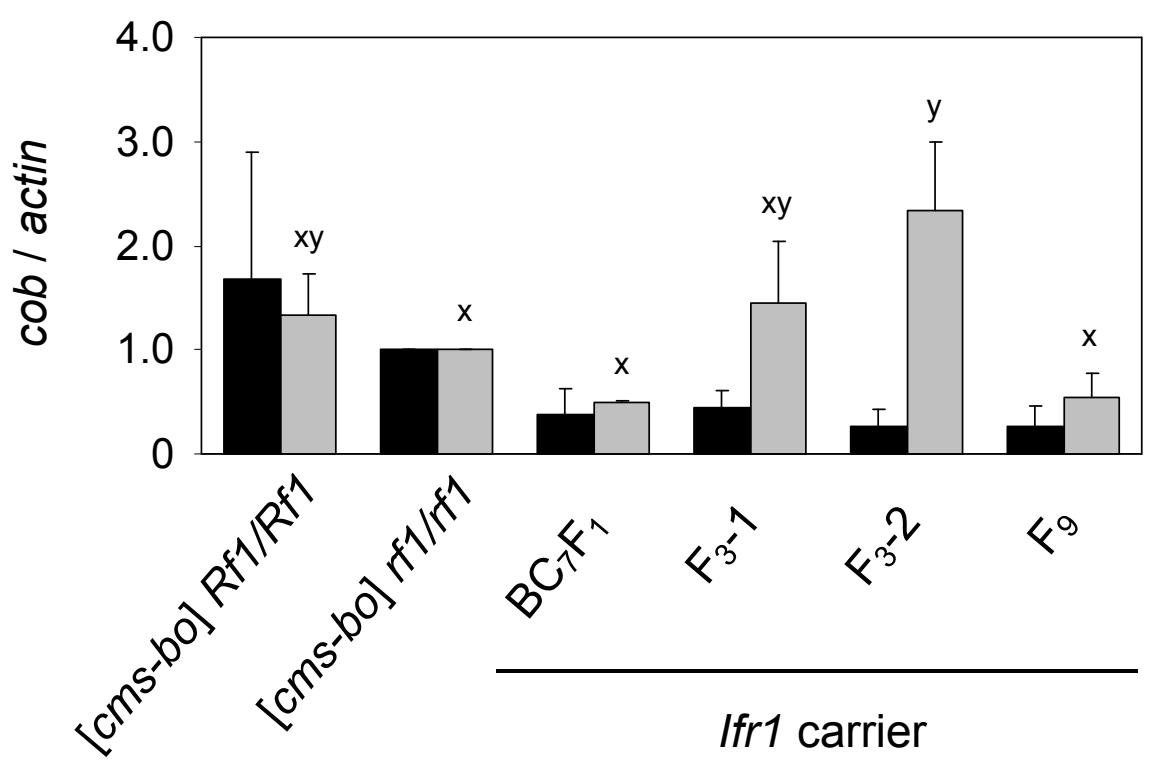

